\title{
Precipitation Extremes in CMIP5 Simulations on Different Time Scales
}

\author{
HUAN ZHANG AND KLAUS FRAEDRICH \\ Max Planck Institute for Meteorology, and University of Hamburg, Meteorological Institute, KlimaCampus, \\ Hamburg, Germany \\ RICHARD BLENDER AND XIUHUA ZHU \\ University of Hamburg, Meteorological Institute, KlimaCampus, Hamburg, Germany
}

(Manuscript received 22 November 2012, in final form 29 January 2013)

\begin{abstract}
Precipitation maxima in global climate model (GCM) simulations are compared with observations in terms of resolution dependence and climate change. The analysis shows the following results: (i) the observed scaling law relating precipitation maxima to duration is basically reproduced but exhibits resolution dependence, (ii) the intensity of precipitation extremes is up to one order of magnitude smaller in the model data, and (iii) the increase of precipitation maxima on short time scales in the warmer climate simulations [representative concentration pathway 8.5 (RCP8.5)] vanishes for monthly time scales.
\end{abstract}

\section{Introduction}

The expected changes of extreme rainfall events under climate change have attracted considerable research efforts in the last years, mainly because of the occurrence of floods and the related damages (Benestad 2006; Kattsov et al. 2007; Holman and Vavrus 2012). In the present publication, the notion "extreme" will be used for global maximum precipitation events. In 1950 Jennings discovered the startling relationship $P \sim d^{b}$, with $b \approx 0.5$ between the global maximum of rainfall $P$ and durations $d$. This simple relation is valid in a range from minutes to years (Jennings 1950) and, hence, on six orders of magnitude. The aim of the present analysis is to assess the ability of global climate models to represent this behavior on daily to annual time scales. Simulations of two climate models contributing to phase 5 of the Coupled Model Intercomparison Project (CMIP5) present-day and global warming experiments [representative concentration pathway 8.5 (RCP8.5)] are used. The main questions are:

- Can simulations reproduce the intensity of extremes observed on different time scales?

Corresponding author address: Huan Zhang, KlimaCampus, University of Hamburg, Grindelberg 5, 20144 Hamburg, Germany. E-mail: huan.zhang@zmaw.de
- Do extremes in a warmer climate increase simultaneously on all different time scales compared to the present-day climate?

Jennings' (1950) results entered hydrology textbooks, papers, and reports and have been substantiated since with more stations and extended records becoming available (Paulhus 1965; Eagleson 1970, p. 200, Fig. 11-25; Hubert et al. 1993; World Meteorological Organization, 1986, 1994; Galmarini et al. 2004). But, to our knowledge, there is no analysis of global climate model (GCM) simulations verifying the observed maximum rainfall depthduration scaling.

The simulations considered in this study are briefly described in section 2. A comparison of the extreme events in simulations with observations by revisiting the scaling law is presented in section 3 , followed by a brief conclusion.

\section{Models and analysis}

The GCM simulations used in the present analysis are performed by two state-of-the-art coupled ocean-atmosphere general circulation models: ECHAM5/Max Planck Institute Ocean Model (MPI-OM) (hereafter EH5OM) and ECHAM6/MPI-OM (hereafter EH6OM) and Hadley Centre Global Environmental Model-Earth System, version 2 (HadGEM2-ES; hereafter HadGEM), with a spectral and a gridpoint global atmosphere, 
TABLE 1. Simulations of present-day (with different resolutions) and future climates.

\begin{tabular}{cclc}
\hline \hline Coupled model & Atmospheric resolution & \multicolumn{1}{c}{ Experiment } & Record length \\
\hline HadGEM & N96L38 & RCP8.5 (daily sampling) & $2006-2100$ \\
HadGEM & N96L38 & Historical (daily sampling) & $1860-2005$ \\
EH6OM & T63L47 & RCP8.5 (daily sampling) & $2006-2200$ \\
EH6OM & T63L47 & Historical (daily sampling) & $1850-2005$ \\
EH5OM & T63L31 & Historical (6-hourly sampling) & $1860-2000$ \\
EH5OM & T31L19 & Historical (6-hourly sampling) & $1800-2000$ \\
\hline
\end{tabular}

respectively. The models are being developed by the Max Planck Institute for Meteorology and the Hadley Centre participating in the CMIP5 runs. A detailed description of ECHAM5 is given by Roeckner et al. (2006), ECHAM6 by Stevens et al. (2013), and HadGEM by Jones et al. (2011). Table 1 summarizes the basic information on horizontal and vertical resolutions, temporal resolutions, and simulation lengths. Present-day climate ECHAM simulations are compared to estimate resolution dependence. For future climate simulations based on the representative concentration pathways, we selected RCP8.5 with a continuous rise in radiative forcing during the twenty-first century leading to a value of about $8.5 \mathrm{~W} \mathrm{~m}^{-2}$ in 2100 because, if Jennings' scaling law exists in the simulation of the high emission scenarios, we may expect it to hold also for those with less emission. For comparison, historical simulations for 1860-2005 by the same models are also analyzed.

We analyze the simulations without bias correction to focus on the models' nonlinear scaling behavior of extremes, although climate models are incapable of providing the correct magnitude of global precipitation (see, e.g., Haerter et al. 2011). Furthermore, recent developments of bias corrections for precipitation (Haerter et al. 2011) suggest a cascade of time scales to be considered, ranging from daily via monthly to annual periods, which, however, could modify the models' intrinsic scaling behavior.

The greatest rainfall depths for different durations are extracted, first by running a duration window to search for the maximum total precipitation $P$ from all gridpoint time series at land and at sea separately, and second by continuing with different window lengths $d$ to assess the relationship $P=P_{0}\left(d / d_{0}\right)^{b}$. Precipitation $P$ and $P_{0}$ are in millimeters, and duration $d$ and $d_{0}$ are in hours. The monthly maximum $P_{0}$ is used to quantify the deviations of simulated from observed records.

\section{Results}

The global observed maximum precipitation-duration relation serves as a reference to compare the simulated data from land and ocean grid points, which range from either $6 \mathrm{~h}$ or 1 day to $1 \mathrm{yr}$. The scaling law relationship $P=P_{0}\left(d / d_{0}\right)^{b}$ is addressed by a log-log comparison with the exponent $b \approx 0.5$ representing the slope while the logarithm of $P_{0}$ is given by the intercept (Fig. 1a). The results of the simulations are displayed in the same manner with slopes obtained by a least squares fit (note that the simulated data are shifted to avoid overlaps; the corresponding factors are included in Fig. 1a). The following subsections explain the results.

\section{a. Scaling law relationships simulated}

The maximum precipitation-duration scaling law exponents are $b \approx 0.5$ in the higher resolutions is obtained (EH5OM T63L31, EH6OM, and HadGEM) compared to $b \approx 0.7$ for the lower-resolution model EH5OM (T31L19). The increase from 0.5 to 0.7 (with decreasing resolution) may indicate a random process modified by enhanced persistence (Zhu et al. 2010). Employing the generalized structure function analysis (Harris et al. 2001) to the 6-hourly time series at those grid points which contribute to the maxima selected for Jennings' scaling law (from T63L31 to T31L19 resolution) lead to the Hurst exponents as a measure of autocorrelation or persistence. It is obvious that a reduced temporal resolution reduces the duration range to three (two) orders of magnitude given the 6-hourly (daily) sampling, compared with the range of six orders of magnitude in observations, which include rainfall events measured in minutes.

\section{b. Locations and durations of rainfall maxima}

In simulations with EH5OM (T63L31), EH6OM, and HadGEM resolutions associated with short duration ( $\leq 5$ days), the maxima originate from different locations distributed in Russia, northern China, and Australia, which are distributed over a wide range of latitudes, while longer durations ( $>5$ days) comprise only a few rain spells that occur mostly in the southwest border of Tibet and Papua New Guinea (Fig. 1b). Rainfall maxima over the ocean are distributed over a wide range of locations in the Pacific and the eastern Bay of Bengal. A similar behavior is observed over land (Jennings, 1950; Galmarini et al. 2004): rainfall maxima with durations 

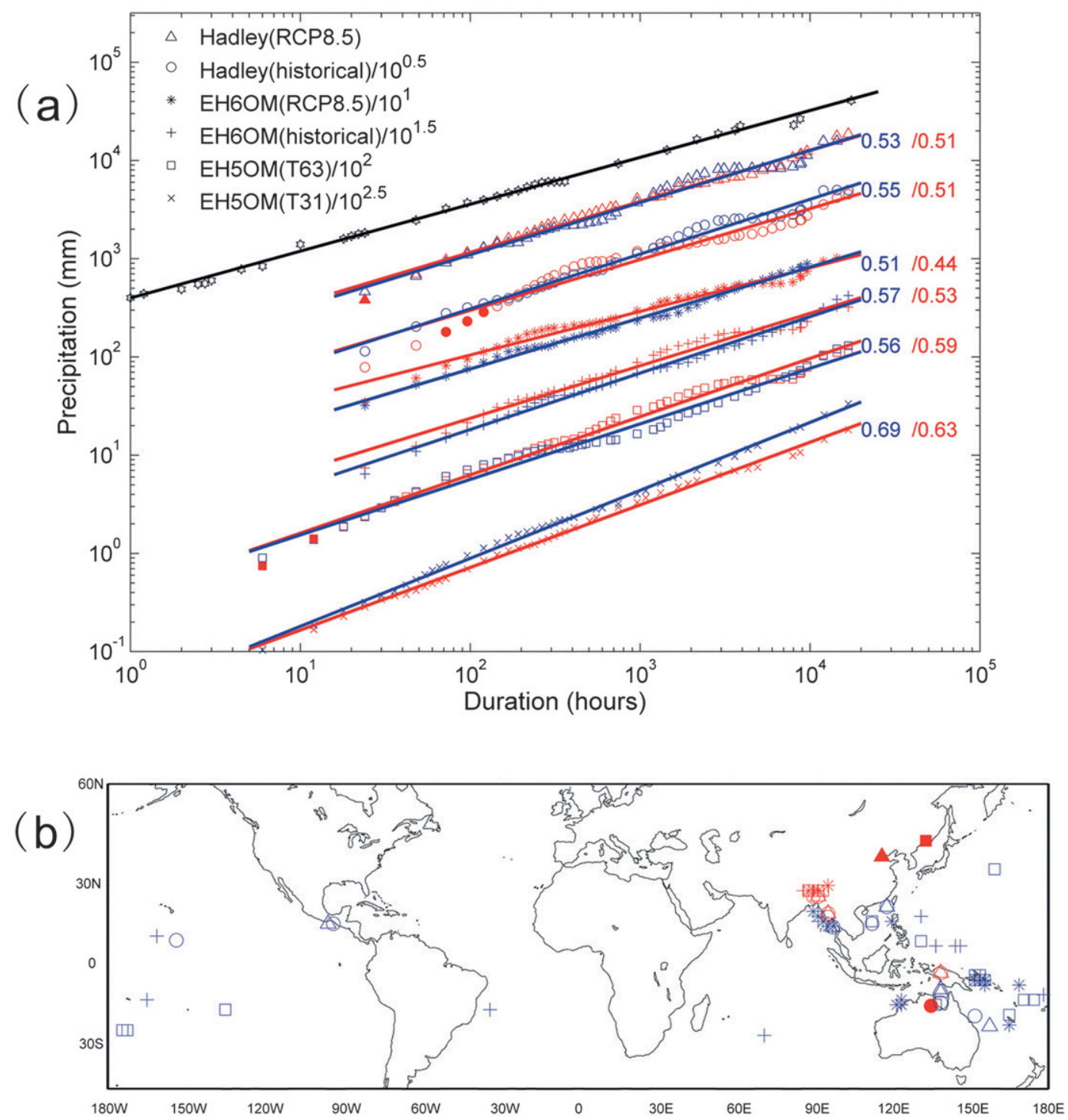

(c)

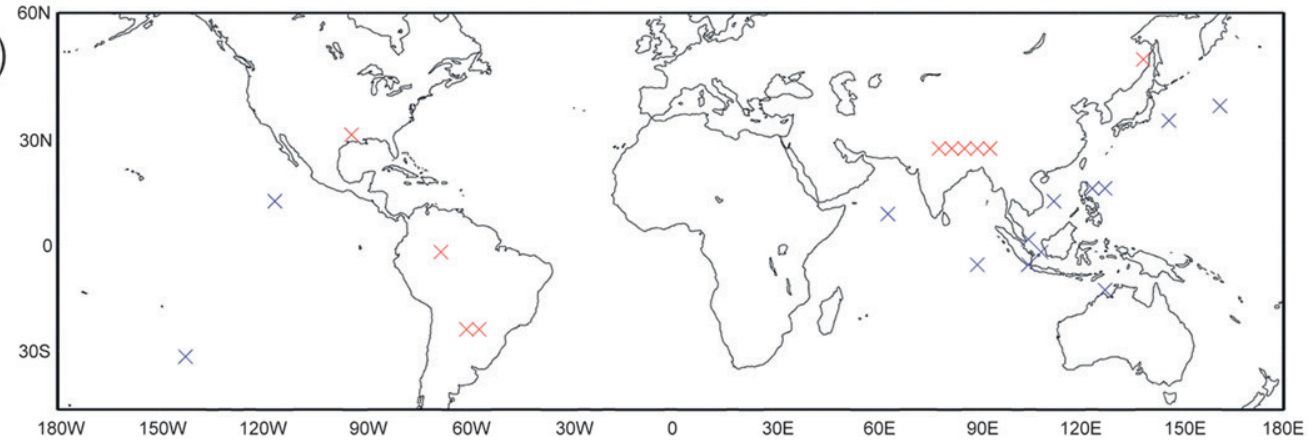

FIG. 1. (a) Maximum precipitation-duration diagram from observed station data (black) and simulated gridpoint values over land (red) and ocean (blue). To avoid overlaps simulated records are shifted by the indicated power of 10 for each model; solid lines indicate least squares fit for land and ocean. Geographical locations of gridpoint data in simulations with (b) EH5OM (T63L31), EH6OM, and HadGEM, and (c) T31L19 resolution [symbols as in (a)]. 


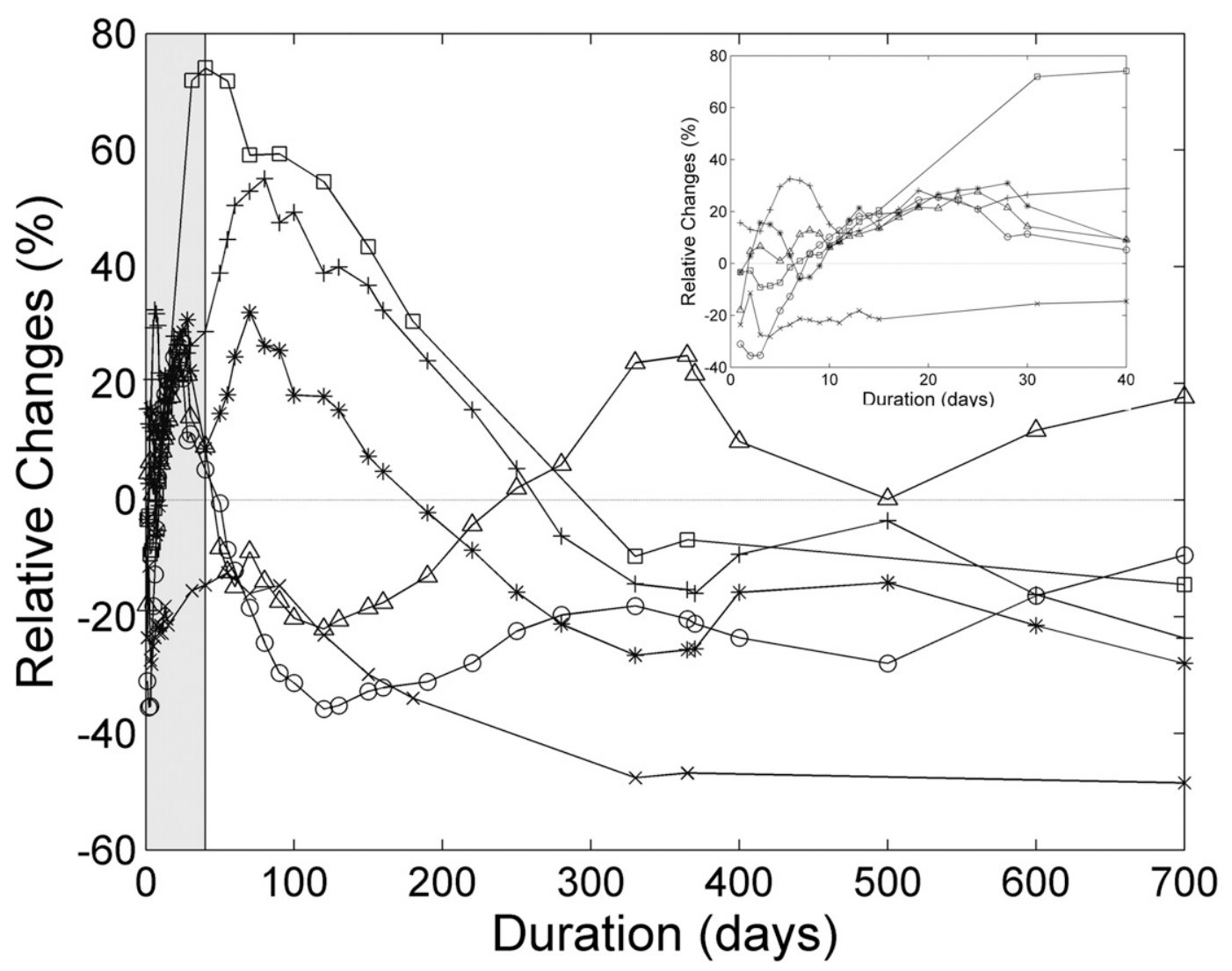

FIG. 2. Land-ocean comparison. Relative changes of maximum precipitation vs duration between maxima over land compared to ocean for different simulations (symbols as in Fig. 1a): Hadley (RCP8.5, triangles), Hadley (historical, circles), EH6OM (RCP8.5, asterisks), EH6OM (historical, pluses), EH5OM (T63L31, squares), and EH5OM (T31L19, crosses). Inset expands shaded area for first 40 duration days.

shorter than 6 days are reported from different locations in the tropics and subtropics, while for longer durations, worldwide rainfall records consist of three rain spells from the tropical locations Cherrapunji (India), Commerson, and Foc Foc (La Reunion). In contrast to simulations with T31L19 resolution, land records are scattered over a wide range of latitudes and longitudes (shown in Fig. 1c). It appears that with increasing resolution the topography induces localized rainfall maxima.

\section{c. Rainfall depths}

For all time scales, the magnitudes of maxima are much larger at higher spatial and vertical resolutions (T63L31 versus T31L19). Monthly precipitation maximum $P_{0}$ from the simulations include $940 \mathrm{~mm}$ in EH5OM (T31L19), $1998 \mathrm{~mm}$ in EH5OM (T63L31), $2047 \mathrm{~mm}$ in EH6OM (historical), $2210 \mathrm{~mm}$ in EH6OM (RCP8.5), $3044 \mathrm{~mm}$ in HadGEM (historical), and $3165 \mathrm{~mm}$ in HadGEM (RCP8.5). These values lie far below the observed 1-month maximum of $10867 \mathrm{~mm}$. At all time scales, simulated monthly maxima are distinctly below the observed ones, and the largest deviation of one order of magnitude is found in the simulations with the lowest resolution of T31L19. This is consistent with findings that the amplitude of extremes increases with resolution in simulations performed with models from the same modeling group (Kharin et al. 2007). Thus, for bias correction of global precipitation extremes from high-resolution simulations, the observed monthly maximum $P_{0}$ needs to be adapted to recover Jennings' scaling law. Lowresolution models, however, would require a correct cascade-related scaling exponent.

\section{d. Land and ocean}

On average, the precipitation maxima over land are higher than over ocean in EH5OM (T63T31) for durations below the annual time scale; the opposite holds for EH5OM (T31L19) simulations (Fig. 2). That is, precipitation maxima are higher over oceans than over continents in low-resolution simulations where moisture supply plays the dominant role. With higher resolutions the magnitudes of the rainfall maxima increase in general, 


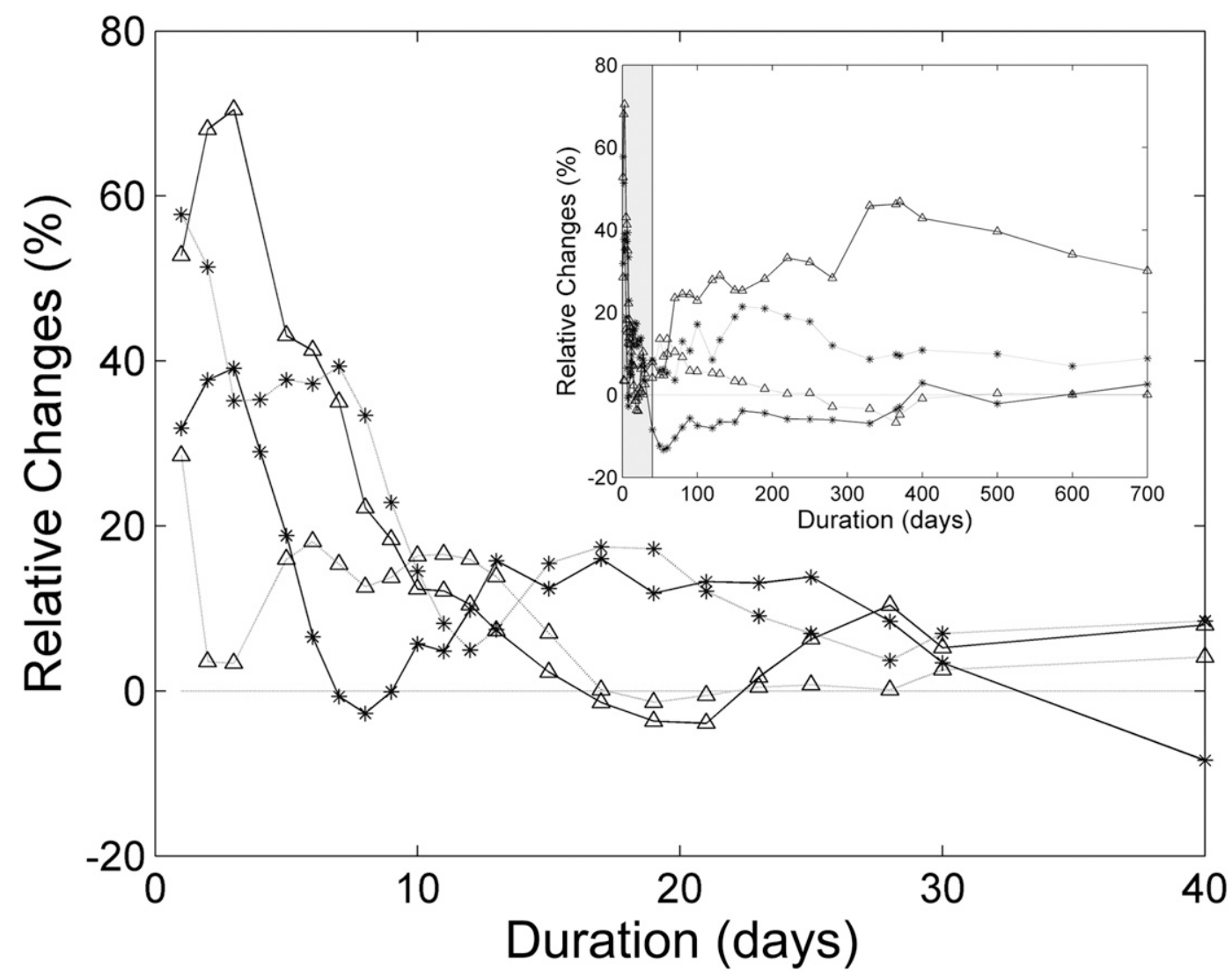

FIG. 3. Warmer and present-day climates: Relative changes of maximum precipitation vs duration between maxima in warm climate scenarios (RCP8.5) compared to present-day simulations over ocean (dotted lines) and land (solid lines) in CMIP5: HadGEM (triangles) and EH6OM (asterisks). Inset shows relative changes beyond first 40 duration days.

but the increments are higher over land than over ocean; this may be caused by increased instability resulting from topographic effects. In a warmer climate, relative changes between the rainfall maxima over land and ocean decrease with longer durations in EH6OM, while they depend on different time scales in HadGEM (Fig. 2).

\section{e. Future climates}

For warmer climates the higher-resolution simulations (RCP8.5, EH6OM, and HadGEM) show that rainfall extremes tend to become more severe at shorter time scales over land (Fig. 3). For durations of days, the maximum rainfall depth increased by about $50 \%$, while there was almost no change in maximum rainfall for durations of months. Durations beyond months the models diverge (Fig. 3, inset): HadGEM simulations report rain maxima increasing by $50 \%$ at annual time scales, while EH6OM rainfall maxima do not change or decrease up to $-10 \%$, compared to their present-day simulations. Rainfall extremes over ocean and land show similar behavior for shorter durations, while for long durations HadGEM remains close to zero and EH6OM increases up to $20 \%$.

\section{f. Second and third maxima}

For all simulations, the second and third rainfall maxima versus duration follow the same scaling law (not shown). The differences between the first, second, and third maxima are less than $10 \%$ at all time scales. That is, the scaling exponent $b$ appears to be independent of the precipitation depth, which may suggest its structure to be monofractal. In addition, missing an individual extreme event does not severely change the scaling relationship. Furthermore, extending the analysis to second/third maxima provides a control on outliers affecting the comparison of records, for example, over land versus sea or present versus future climates (not shown).

\section{Summary and outlook}

The ability of global climate models to reproduce extremes on different time scales is of great importance for climate estimates of the past and the future. Therefore, the comparison with observed functional relationships is useful to verify model performance. The maximum precipitation-duration scaling law $P=P_{0}\left(d / d_{0}\right)^{b}$, with 
$b \approx 0.5$, which has been observed at land stations to hold over a wide duration range, is the basis for the verification analysis of two state-of-the-art global (gridpoint and spectral) climate models. The main results can be summarized as follows:

(i) Jennings' scaling law for the world's maximum precipitation is found in model data covering a wide range of scales with three orders of magnitude (compared to six orders in observations). The scaling exponent $b \approx 0.5$ is found at both land and ocean grid points (and is also observed at land stations). The lower-resolution model follows a larger scaling exponent $(b \approx 0.7)$ as expected for a process with long-term memory. Furthermore, second and third maxima show similar behavior. The analysis of Jennings' maximum precipitation depth-duration scaling law in global climate models may provide guidance for cascade-dependent bias correction not only for the first maxima but also for general extreme precipitation events.

(ii) The simulated precipitation extremes (T31L19 resolution) are about one order of magnitude smaller than the observed ones; this difference is reduced for models with enhanced spatial resolution. Magnitudes of rainfall maxima increase in general with higher resolution (EH5OM, T63L31), but the increments are higher over land than over ocean. In the warmer climate (RCP8.5) the intensity in the maximum precipitation events increases by about $50 \%$ for durations of days but vanishes for monthly time scales.

(iii) In high-resolution simulations (T63L31), the scaling law is composed of rain spells of short duration occurring at different locations, while rainfall extremes of longer durations ( $>5$ days) are located at few grid points and generated by few extreme spells.

Acknowledgments. We thank two reviewers for their valuable comments and acknowledge support by the German Science Foundation (Bundle Project PAK 393 and Cluster of Excellence EXC177 "CliSAP"), by the China Scholarship Council (HZ), and by a Max Planck Society Fellowship (KF, HZ).

\section{REFERENCES}

Benestad, R. E., 2006: Can we expect more extreme precipitation on the monthly time scale? J. Climate, 19, 630-637.

Eagleson, P. S., 1970: Dynamic Hydrology. McGraw-Hill, 462 pp.

Galmarini, S., D. G. Steyn, and B. Ainslie, 2004: The scaling law relating world point-precipitation records to duration. Int. J. Climatol., 24, 533-546.

Haerter, J. O., S. Hagemann, C. Moseley, and C. Piani, 2011: Climate model bias correction and the role of timescales. Hydrol. Earth Syst. Sci., 15, 1065-1079.

Harris, D., E. Foufoula-Georgiou, K. K. Droegemeier, and J. J. Levit, 2001: Multiscale statistical properties of a high-resolution precipitation forecast. J. Hydrometeor., 2, 406-418.

Holman, K. D., and S. J. Vavrus, 2012: Understanding simulated extreme precipitation events in Madison, Wisconsin, and the role of moisture flux convergence during the late twentieth and twenty-first centuries. J. Hydrometeor., 13, 877-894.

Hubert, P., Y. Tessier, S. Lovejoy, D. Schertzer, F. Schmitt, P. Ladoy, J. P. Carbonnel, and S. Violette, 1993: Multifractals and extreme rainfall events. Geophys. Res. Lett., 20, 931-934.

Jennings, A. H., 1950: World's greatest observed point rainfalls. Mon. Wea. Rev., 78, 4-5.

Jones, C. D., and Coauthors, 2011: The HadGEM2-ES implementation of CMIP5 centennial simulations. Geosci. Model Dev., 4, 543-570.

Kattsov, V. M., J. E. Walsh, W. L. Chapman, V. A. Govorkova, T. V. Pavlova, and X. Zhang, 2007: Simulation and projection of Arctic freshwater budget components by the IPCC AR4 global climate models. J. Hydrometeor., 8, 571-589.

Kharin, V. V., F. W. Zwiers, X. Zhang, and G. C. Hegerl, 2007: Changes in temperature and precipitation extremes in the IPCC ensemble of global coupled model simulations. J. Climate, 20, 1419-1444.

Paulhus, J. L. H., 1965: Indian Ocean and Taiwan rainfalls set new records. Mon. Wea. Rev., 93, 331-335.

Roeckner, E., and Coauthors, 2006: Sensitivity of simulated climate to horizontal and vertical resolution in the ECHAM5 atmosphere model. J. Climate, 19, 3771-3791.

Stevens, B., and Coauthors, 2013: The atmospheric component of the MPI-M Earth System Model: ECHAM6. J. Adv. Model. Earth Syst., doi:10.1002/jame.20015, in press.

World Meteorological Organization, 1986: Manual for estimation of probable maximum precipitation. 2nd ed. Operational Hydrology Rep. 1/WMO 332, 269 pp. [Available online http:// library.wmo.int/pmb_ged/wmo_332.pdf.]

_ 1994: Guide to hydrological practices. 5th ed. WMO Rep. 168, 402 pp. [Available online at ftp://ftp.wmo.int/Documents/ MediaPublic/Publications/Guide_to_Hydrological_Practices/ WMOENG.pdf.]

Zhu, X., K. Fraedrich, Z. Liu, and R. Blender, 2010: A demonstration of long-term memory and climate predictability. J. Climate, 23, 5021-5029. 